\title{
El nuevo Código procesal civil francés veinticinco años después
}

Loïc Cadiet

El nuevo código procesal civil francés celebra su vigésimo quinto aniversario y éste no sólo es el momento de conmemoraciones, de recuerdos acerca de su elaboración sino también de reflexión sobre su aporte a la evolución contemporánea del derecho procesal francés.

Este código se elaboró progresivamente a partir de los trabajos de una comisión de reforma del Código procesal civil instituida en 1969 por iniciativa del señor Jean Foyer, profesor de la Facultad de Derecho de París, en ese entonces, presidente de la Comisión de leyes de la Asamblea Nacional, después de haber sido Ministro de Justicia del General de Gaulle. En un primer momento, los trabajos de esta comisión condujeron a la promulgación de cuatro decretos "que instituían nuevas reglas de procedimiento destinadas a formar parte de un nuevo Código procesal civil» o «destinadas a integrarse en el nuevo Código procesal civil $\aleph^{1}$. Sólo en un segundo momento es que este conjunto de textos se modificó y se completó por el Decreto No 75-1123 del 5 de diciembre de 1975 que instituye un nuevo Código procesal civil. El nuevo código entró en vigencia el $1^{\circ}$ de enero de 1976.

Tal cual, el nuevo código no estaba completo ya que se componía solamente de un primer libro dedicado «Disposiciones comunes a todas las jurisdicciones" y de un libro segundo que reúne las «Disposiciones particulares para cada jurisdicción». Se continuó con esta empresa

1 Se trata de los decretos No 71-740 del 9 de setiembre de 1971, No 72-684 del 20 de julio de 1972, No $72-788$ del 28 de agosto de 1972, y No 73-1122 del 17 de diciembre de 1973 
en los años siguientes y sólo fue en 1981 que el nuevo código tomaría la forma que tiene hoy en día con el Decreto No 81-500 del 12 de mayo de 1981: este decreto instituía las disposiciones del tercer y cuarto libros titulados respectivamente "Disposiciones particulares a ciertas materias" y "El arbitraje». En el plan general del nuevo código procesal civil, inicialmente debía figurar un quinto libro relativo a las vías de ejecución. Pero este proyecto fue abandonado ya que el derecho de las vías ejecutivas debían ser objeto de un código autónomo de ejecución. Entonces, la obra de codificación del nuevo procedimiento civil puede considerarse terminada.

Sobre el nuevo Código procesal civil como obra por realizar o realizada, se ha escrito mucho, incluso recientemente ${ }^{2}$; entre aquellos que escribieron sobre él, se encuentran los que recibieron la misión histórica de elaborar la obra ${ }^{3}$. El nuevo Código no sólo suscita interés en relación con el procedimiento civil sino también en relación con el campo de la codificación, técnica particular de ordenamiento del derecho. Más y mejor que cualquier otro, el nuevo código procesal civil simboliza el entusiasmo de los franceses, incluso la "pasión" francesa por los códigos durante la 5 ta. República ${ }^{4}$.

También es interesante completar este enfoque analizando de qué manera la doctrina universitaria francesa ha recibido el nuevo Código procesal civil, desde 1975 hasta la fecha.

Digamos de entrada que, a pesar de las críticas a veces agudas, el nuevo Código más bien ha sido bien recibido por los autores y que este recibimiento favorable incluso ha ido consolidándose en el transcurso de los años. Ha sido bien recibido porque el antiguo Código procesal civil, de 1806 estaba muy desprestigiado y desde hace mucho tiempo,

2 J. Herón, "Le nouveau Code de procédure civile" (El nuevo Código procesal civil), en B. Beignier (dir.), La codification (La codificación), Dalloz, 1997, pp. 81-89.

3 Véase especialmente G. Gomu, "La codification de la procédure civile en France» (La codificación del procedimiento civil en Francia", Revue juridique et politique (Revista jurídica y política), 1986, p. 689 y ss. - "L'élaboration du Code de procédure civile» (La elaboración del Código procesal civil", Revue d'histoire des facultés de droit et de la science juridique, (Revista de historia de las facultades de derecho y de ciencia jurídica), 1995, No 16, p. 241 y ss.

4 Véase J. Carbonnier, Droit et passion du droit sous la Véme République (Derecho y pasión por el derecho en la 5ta. República), Flammarion, 1996. 
era una pálida copia de la Ordenanza civil de 1667 , ya se había dicho de éste que era viejo desde que naciós. También fue bien recibido porque este Código, nuevo en su forma, también lo era en cuanto a sus disposiciones: según una expresión consagrada ${ }^{6}$, de lo que se trataba era de una verdadera «codificación-reforma»; lo que consagraba era una verdadera reforma del procedimiento civil. El proceso civil salía renovado.

Este recibimiento se puede analizar desde dos puntos de vista.

El Código en primer lugar, se recibe por lo que es formalmente, es decir, una obra compuesta por artículos numerados de manera continua, más o menos largos, distribuidos según un plan dividido en libros, títulos, subtítulos, capítulos, secciones y muchas otras subdivisiones más. El Código es en primer lugar eso, lo que deja aparecer, lo que muestra, su aspecto, su forma, una manera de ser un Código. Y es así como al principio el Código es captado por la doctrina.

Pero esta obra de legislación no es ni el fruto del azar ni el de una recopilación. El nuevo Código procesal civil ha sido reflexionado y ha sido pensado en función de cierta concepción del proceso civil ya que del proceso civil se pueden tener varias concepciones según la manera en que se distribuyen los papeles entre los diferentes actores del teatro judicial. Entonces, el Código ha recogido esta doctrina de conjunto en sus disposiciones y esta doctrina, todavía se lee a través de éstas. No se puede presentar el Código sin presentar la doctrina captada así por el Código.

El Código captado por la doctrina (I) y la doctrina captada por el Código (II), son los dos puntos de vista que conviene adoptar, cada uno en su momento.

\section{El nuevo Código procesal civil captado por la doctrina}

Aquí está entonces el Código, instituido por un decreto del 5 de diciembre de 1975. Como código incompleto de 972 artículos en 1975 ,

5 E. Glasson, A. Tissier y R. Morel, Traité théorique et pratique d'organisation judiciaire, de compétence et de procédure civile (Tratado teórico y práctico de organización judicial, de competencia y de procedimiento civil).

6 Véase Ph. Malaurie, "Rapport de synthése" (Informe de síntesis), en La codification (La codificación), citado anteriormente, pp. 201-202. 
y código completo de 1507 artículos en 1981, el nuevo código procesal civil es captado por la doctrina en su estado bruto, conocido antes de ser reconocido: el juicio de hecho (A) precede al juicio de valor (B).

\section{A. El juicio de hecho}

Si bien las palabras para decirlo varían de un autor a otro, es la misma realidad la que salta a la vista de los primeros comentaristas del Código. El nuevo código procesal civil es en primer lugar un plan $\left(1^{\circ}\right)$; y luego un estilo $\left(2^{\circ}\right)$.

\section{Un plan}

El plan del antiguo código procesal civil no destacaba por su racionalidad. Tenía dos partes. La primera, titulada Procedimiento ante los tribunales, comprendía cinco libros dedicados respectivamente a la justicia de paz, a los tribunales inferiores, a los tribunales de apelación, a las vías extraordinarias para impugnar las sentencias y a la ejecución de estas últimas. La segunda, titulada Procedimientos diversos, comprendía, por su parte, tres libros: el libro I no tenía título y estaba dividido en doce títulos inconexos, mientras que el libro II trataba los Procedimientos relativos a la apertura de una sucesión y el libro III, Arbitrajes, en un título único. Se puede decir que este índice no tenía ningún sentido, que era un plan heredado de la historia más que deseado por el legislador de 1806.

Por el contrario, el reto de la codificación que animaba a los reformistas del procedimiento civil del siglo XX los condujo, rápidamente, al asunto del plan del código. Como se lo explica uno de ellos, «llega un momento en que, para distribuir los temas en otra forma diferente a la de un catálogo, es necesario vincularlos en un orden racional ${ }^{7}$. El plan del nuevo código procesal civil es pues una obra racional.

Después de haber intentado organizar el Código partiendo del procedimiento ante el tribunal de primera instancia, los redactores del

7 G. Cornu, "L'élaboration du code de procédure civile" (La elaboración del código procesal civil), op. cit, p. 247. 
Código terminaron por convencerse de que era necesario razonar, a un nivel superior de generalidad, acerca del propio juez civil, partiendo del postulado de que existe un "proceso civil tipo".

«En esta perspectiva, el procedimiento ante el tribunal de primera instancia dejaba de ser el arquetipo, para convertirse en una de las manifestaciones paralelas de las reglas que gobiernan en general el proceso civil, todo proceso civil como base genérica. El plan había nacido. El libro primero del código debía estar orientado a establecer las reglas de procedimiento comunes a todas las jurisdicciones, reglas fundamentales aplicables después de haber abstraído la naturaleza de cada jurisdicción. El libro segundo estaba dedicado a enunciar, jurisdicción por jurisdicción, las reglas particulares de cada una, en primera instancia, apelación y casación; es la parte realizada, en el procedimiento, según la naturaleza de la jurisdicción. Introduciendo otro criterio tomado de la materia del litigio, el libro tercero estaba destinado a reunir las disposiciones particulares a ciertas materias, es decir, a considerar, en su momento, los procedimientos que están sometidos a reglas especiales en razón de la materia (divorcio, asistencia educativa, acción posesoria, etc.) $)^{8}$.

Luego, incorporándose al todo, en razón de su doble especialidad de procedimiento y material, venía un libro cuarto relativo al arbitraje. Este enfoque metodológico no se limita a la arquitectura general del código. "En su orden» se ha escrito, «este enfoque también es un modelo" ${ }^{9}$. En lo que se refiere a sus subdivisiones como a sus divisiones principales, el código procede también de lo general a lo particular, las reglas de principio preceden a las reglas complementarias y de excepción, siendo las disposiciones comunes las que a menudo se enuncian antes de la exposición de las disposiciones particulares a cada variedad ${ }^{10}$ : las reglas relativas a las medidas de instrucción ${ }^{11}$, como aquellas

8 G. Cornu, op. cit., p. 248.

9 G. Cornu, op. cit. y loc. cit.

10 Lo más a menudo, pero no siempre. Sucede que las disposiciones particulares se expongan antes de las disposiciones comunes. ¿La razón posible? La inteligencia de las primeras implica el conocimiento previo de las primeras: véase por ejemplo los arts. $49^{\circ}-52^{\circ}$, para las disposiciones comunes a la competencia de atribución y a la competencia territorial; arts. $984^{\circ}$ a $955-2$, para las disposiciones comunes a los pro- 
que se refieren a las vías de recursos ${ }^{12}$, son particularmente significativas al respecto ${ }^{13}$. Como se ha sugerido, este «enfoque de ciencia legislativa" respondía a un "deseo de economía legislativa": "hacer que destaque lo mismo bajo lo diverso produce una economía de textos y de derechon ${ }^{14}$.

En resumen, este orden racional no excluía el hecho de que se tuviera en cuenta, a modo de complemento, la cronología del proceso. Esta cronología reaparece, en lo esencial, en la sucesión de los títulos que componen el libro primero de las disposiciones comunes.

En el sentido completo el término, el plan del nuevo código procesal civil aparece pues como una obra de composición y así, como se ha escrito, "un código bello, es un plan bello bien ordenado" ${ }^{15}$, entonces el nuevo código procesal civil seguramente es un código bello cuyo diseño francés tenemos que admirar. La elegancia del estilo no desmerece la elegancia del plan ya que el nuevo código procesal civil, también es un estilo.

\section{$2^{\circ}$ Un estilo}

La lengua del código de 1806 transmitía los conceptos y, a menudo, las maneras de la ordenanza real de 1667. En estas condiciones, el nuevo código sólo podía ser "moderno" y así aparece, a primera vista, a sus primeros comentaristas ${ }^{16}$.

Pero no se trata solamente de emplear los términos de fines del siglo $\mathrm{XX}$ para hacerse comprender por el hombre y la mujer de fines del

cedimientos contenciosos y al procedimiento gratuito en apelación; arts. $1009^{\circ}$ a 1022-1, para las disposiciones comunes a los diferentes procedimientos ante la Corte de casación.

11 Véase arts. $143^{\circ}-178^{\circ}$, así como arts. $204^{\circ}-221^{\circ}$, para la encuesta y arts. $232^{\circ}$ $248^{\circ}$, para las medidas de instrucción ejecutadas por un técnico.

12 Véase arts. $528^{\circ}-537^{\circ}$.

13 Véase igualmente a propósito de las intervenciones forzadas, arts. $331^{\circ}-333^{\circ}$; de las sentencias, arts. $430^{\circ}-479^{\circ}$.

14 G. Cornu, op. cit., pp. 248-249.

$15 \mathrm{Ph}$. Malaurie, "Rapport de synthése» (Informe de síntesis), en La codification (La codificación), op. cit, p. 200.

16 Véase P. Catala y F. Terré Procédure civile et voies d'exécution (Procedimiento civil y vías de ejecución), Presse universitaires de France, 2da. ed. 1976, p. 20. 
siglo XX. Esta obra de legislación no es una obra literaria. Una doble preocupación anima pues a los redactores del nuevo código.

La preocupación, en primer lugar, «por evitar las ambigüedades relacionadas a la polisemia de muchos términos del lenguaje jurídico ${ }^{17}$. En este código, un mismo término siempre debe designar lo mismo y no se debe emplear con sentidos diferentes ${ }^{18}$ : así, el término juez designa la jurisdicción y no sólo a la persona del juez, a diferencia del tribunal concebido como colegio; así, el término "demanda» designa el acta jurídica por la cual un litigante emite una pretensión y no la pretensión por sí misma. El contenido de la convención puede ser impugnado, pero no su principio que es conforme con el nominalismo necesario de la ley.

De ahí, luego, la preocupación correlativa de definir las nociones fundamentales sobre las que reposan las principales reglas del código. "Es a través de definiciones legales" -más de treinta-19 "que el código nos advierte del sentido único" ${ }^{20}$ que le da a esas nociones: lo que debemos comprender por «asunto que se somete a la jurisdicción voluntaria $»^{21}$, por «lugar donde vive el demandado $»^{22}$, por «citación»" ${ }^{23} \mathrm{o}$ «demanda suscrita conjuntamente por las partes litigantes» ${ }^{24}$, por «reconvención »" «adicional» ${ }^{26}$, «intervención $»^{27}$.

Muchos años después de la promulgación del nuevo código, uno de sus redactores expresará claramente esta preocupación de la siguiente manera: «el derecho codificado es portador de un lenguaje codificado. Éste ofrece claves de lectura. Ya es un tipo de razonamiento» ${ }^{28}$. Y es

17 J. Héron, Droit judiciaire privé (Derecho judicial privado), Montchrestien, 1991 , No 17.

18 Sobre esta elección, véase G. Cornu, op. cit., p. 249.

19 Véase L. Coupet, "Les définitions dans le Code de procédure civile» (Las definiciones en el Código procesal civil), Revue de la recherche juridique (Revista de la investigación jurídica), 1987, No 4, pp. 1051-1062.

20 Ibídem.

21 Art. $25^{\circ}$.

22 Art. $43^{\circ}$.

23 Art. $55^{\circ}$.

24 Art. $57^{\circ}$.

25 Art. $64^{\circ}$.

26 Art. $65^{\circ}$.

27 Art. $6^{\circ}$.

28 G. Cornu, op. cit., p. 250. 
además otra cosa, la gracia que viene por añadidura, el hecho de que la pluma que expresa el verbo de la ley haya sido de rara elegancia ${ }^{29}$. El juicio de valor se vislumbra ya bajo el juicio de hecho.

\section{B. El juicio de valor}

Efectivamente, el juicio de valor se vislumbra bajo el juicio de hecho. Pero también se expresa de manera diferente, a través de apreciaciones a veces favorables y a veces desfavorables, o simplemente matizadas. Lo más importante es que el juicio de valor madura con el tiempo. Existe el tiempo de las primeras impresiones, en caliente, más bien apasionadas $\left(1^{\circ}\right)$, después, con la distancia, el tiempo sino del balance, por lo menos de las evaluaciones más razonadas $\left(2^{\circ}\right)$ : la tendencia general es la de una preferencia que va acrecentándose.

1. El juicio doctrinal en su esencia

Al día siguiente de su publicación, el nuevo código procesal civil fue objeto, en lo esencial, de una apreciación positiva (a). Y las críticas que se le hicieron sólo aparecieron, prudentemente, acompañando esta apreciación (b).

A) Dicho compendio célebre de Procedimiento civil, traduce de manera ejemplar la recepción favorable reservada a la forma del nuevo Código procesal civil. Allí leemos estas líneas en un párrafo dedicado a la "Presentación formal del nuevo Código".

"La presentación material ha sido cuidada de manera especial» «la lengua jurídica sale a la vez depurada y enriquecida de esta obra de codificación» «La redacción del nuevo Código procesal civil parece ser el ejemplo más logrado en el derecho contemporáneo, de la precisión técnica unida a la claridad» «El plan adoptado para la presentación de los nuevos textos también es digno de ser destacadon ${ }^{30}$.

29 J. Héron, op. cit., y loc. cit.

$30 \mathrm{~J}$. Vincent y S. Guinchard, Procédure civile (Procedimiento civil), Dalloz, 20 ed., 1981, No 10, p. 22. 
La forma del Código no sólo es juzgada como tal, por sus cualidades intrínsecas. A instancia de los señores Catala y Terré, los autores ven ahí la ilustración de "algunas grandes ideas" ${ }^{31}$ : así por ejemplo "la clarificación del lenguaje jurídico y la formulación de definiciones claras» ${ }^{32}$ son consideradas como la manifestación del «deseo de alentar y de facilitar el acceso a la justicia»" ${ }^{33}$. En cuanto al plan, que se abre sobre las disposiciones comunes a todas las jurisdicciones, éste es considerado revelador del «deseo de unidad» de los redactores del Código, lo que confirma la adopción de una numeración continua de los artículos.

B) Si se quiere poner de lado las críticas, a veces severas, dirigidas a la manera como ha sido concebida su elaboración, como autor eminente que llega hasta a considerarla deplorable $e^{34}$, la forma del nuevo Código procesal civil recibe principalmente el reproche de ser demasiado doctrinal.

«Este Código se presenta un poco a la manera de un tratado o de un manual» escribe el señor Perrot, para quien «la fórmula es racionalmente seductora" pero "un poco desconcertante para el profesional que para encontrar la solución a un asunto está obligado a remitirse a varios textos diseminados en el Códigon. Y también se le reprocha el hecho de tomar el ejemplo de los enunciados que deben figurar en una citación ante el tribunal de primera instancia ${ }^{35}$.

Más allá de su aspecto técnico, otros autores extienden la queja a la concepción misma del Código. El reproche, realmente, se presenta como un lamento, el que:

«[...] hecho poco común sobre todo en procedimiento civil francés, la presencia de los profesionales en la Comisión no haya podido evitar que este conjunto parezca un poco como un "Professenrecht", un dere-

31 P. Catala y T. Terré, op. cit., p. 20.

32 P. Catala y F. Terré, op. cit., y loc. cit.

33 Ibídem.

34 P. Catala y F. Terré, op. cit., y loc. cit.

$35 \mathrm{Su}$ conocimiento impone consultar tres artículos diferentes, los artículos $56^{\circ}$, $648^{\circ}$ y $752^{\circ}$ del Código: Véase R. Perrot, op. cit., p. 33. 
cho de profesores más adecuado para manejar ideas que para manejar expedientes reales en litigios concretos y particularess ${ }^{36}$.

Son otros profesores de derecho los que lo escriben. Pero el reproche desaparecerá en las ediciones posteriores de la misma obra ${ }^{37}$ lo que indica la evolución del juicio doctrinal. ¿Cuál es ese juicio veinticinco años después?

2. El juicio doctrinal veinticinco años después

Un cuarto de siglo después, el balance muestra un incremento de los elogios (a) y un desplazamiento de las críticas (b).

a) El incremento de los elogios se manifiesta

Ahí donde, apenas creado el Código, esos autores escribían:

"Todavía es muy pronto para emitir un juicio objetivo sobre este conjunto de disposiciones que constituyen sin ninguna duda el monumento legislativo y reglamentario más importante que se haya dado en materia de procedimiento civil desde la época de Napoleón» ${ }^{38}$.

Hoy ellos mismos escriben:

"Este conjunto de disposiciones constituye sin duda el monumento legislativo y reglamentario más importante que se haya dado en materia de procedimiento civil desde la época de Napoleón ${ }^{39}$.

La modificación podría hacer sonreír si sólo viéramos en ella una simple corrección de estilo impuesta por el paso del tiempo, de esas que todos los autores -y es la manera más fácil- no dejan de hacer de una edición a otra de sus obras. Pero este no es el caso. Veinticinco años después, el nuevo Código de procedimiento civil es, en efecto,

36 J. Vincent y S. Guinchard, op. cit., 20 ed. 1981, No 10, p. 25.

37 Véase por ejemplo J. Vincent y S. Guinchard, op. cit., 24 ed., 1996, No 31 a 41 .

38 J. Vincent y S. Guinchard, op. cit., 20 ed. No 11.

39 J. Vincent y S. Guinchard, op. cit., 24 ed. No 40. 
recibido como un modelo de codificación y no sólo por los especialistas en procedimiento civil. Si Jacques Héron ve en esto «la obra legislativa más importante de estos últimos veinte años» que se desprende "fácilmente de una legislación a menudo mediocre, a veces deletérea o incluso criminal" ${ }^{40}$, "el ejemplo perfecto del éxito de una codificación en el sentido verdadero y pleno del término», «en una palabra, [...] el modelo de todos los códigos modernos ${ }^{41}$, este juicio es compartido por otro autor que lo considera como «el único gran código actual, el único que Stendhal leería actualmente con gusto" $"$. No es sólo su forma la que sigue siendo alabada, «notable» escriben ${ }^{43}$. «En el fondo» añaden, "sus virtudes no son menores" ${ }^{44}$ y la distancia en el tiempo hace aparecer al nuevo Código procesal civil como «una obra ampliamente meditada y madura por sus autores antes de que se escribiera la primera línea $x^{45}$. ¿Acaso estará en marcha un proceso de idealización doctrinal del Código? No faltarán aquellos que lo sugieran.

Sin embargo, esto no significa que el nuevo Código procesal civil haya sido santificado o deba serlo. Siempre recibe críticas pero es importante que éstas hayan disminuido, sino totalmente, por lo menos en gran medida.

b) ¿Acaso el Código procesal civil es demasiado doctrinal? «Dividiendo sus categorías", jacaso no se habrá "sacrificado por la teoría jurídica»? ${ }^{46}$ Veinte años después, uno de los autores del nuevo Código respondió al reproche del Professenrecht $t^{47}$ y su respuesta transmite convicción.

$40 \mathrm{~J}$. Héron, Droit judiciaire privé (Derecho judicial privado), Montchrestien, 1991, No 17.

$41 \mathrm{~J}$. Héron, "Le nouveau Code de procédure civile» (El nuevo Código de procedimiento civil), en La codification (La codificación) citado anteriormente, p. 81 y ss., esp. $\mathrm{N}^{\circ} 2$.

42 B. Beignier, "Avant-propos» (Prólogo), en La codification (La codificación), op. cit., p. 2.

43 J. Héron, Droit judiciaire privé, (Derecho judicial privado) op. cit., No 17.

$44 \mathrm{~J}$. Héron, op. cit., No 18.

$45 \mathrm{~J}$. Héron, op. cit., y loc. cit.

46 G. Cornu, "L'élaboration du code de procédure civile" (La elaboración del código procesal civil), op. cit., p. 252.

47 Véase supra $1^{\circ}$ y G. Cornu, op. cit., pp. 250-255. 
El nuevo Código incluye efectivamente definiciones, pero esto sólo tiene "un interés práctico dirigido a aclarar las nociones que sirven diariamente para ofrecer la justicia ${ }^{48}$. El asunto es particularmente claro cuando se trata de los medios de defensa (defensas en cuanto al fondo, desestimación y excepciones de procedimiento) ${ }^{49}$. Aclarando "el sentido de las instituciones reglamentadas" ${ }^{50}$, estas definiciones permiten reducir, e incluso evitar los contenciosos de interpretación que de esta manera se pueden ahorrar. La observación está justificada, salvo señalando que el nuevo Código procesal civil puede haber omitido algunas definiciones que no tienen esta virtud operativa: al respecto, la definición que se da a la acción en justicia por el artículo $30^{\circ}$ es un ejemplo generalmente bastante criticado ${ }^{51}$, incluso por los más fervientes admiradores del Código ${ }^{52}$.

En última instancia y de manera paradójica, actualmente, el Código procesal civil recibe el reproche justamente inverso, el de no haber ido lo suficientemente lejos en la concepción doctrinal de sus reglas, frustración de autores con apetito pero cuya hambre, disfrazada de esta manera, sigue en parte insatisfecha.

Insatisfecha a propósito del plan, en primer lugar. Ya en 1976 se lamentaba de que las disposiciones propias al procedimiento de la Magistratura del Trabajo se hubieran dejado en el Código del trabajo, en lugar de ser integradas al nuevo código procesal civil donde figuran sólo a través del «procedimiento insólito que consiste en citarlas en el artículo $879^{\circ}{ }^{53}$, semejante precaución tampoco se tomó para las dis-

48 G. Cornu, op. cit., p. 252.

49 G. Cornu, op. cit., y loc. cit.

50 J. Héron, Droit judiciaire privé (Derecho judicial privado), citado anteriormente, No 17.

51 Véase not. H. Croze y C. Morel, Procédure civile (Procedimiento civil), Presses universitaires de France, 1988, pp. 131-132 y No 135 p. 140 - L. Cadiet, Droit judiciaire privé (Derecho judicial privado), Litec, 3 de. 2000, No 782-783.

52 Véase p. Ex. J. Héron, "Le nouveau Code de procédure civile» (El nuevo Código procesal civil) citado anteriormente, No 15: «estos conceptos no dependen, estrictamente hablando, de la voluntad del legislador, sino de la ciencia del derechon y que la ley ya no tiene que definir, en procedimiento, la acción que la retroactividad en derecho de los conflictos de leyes en el tiempo o la calificación, en derecho internacional privado.

53 P. Catala y F. Terré, op. cit., pp. 20-21. 
posiciones propias a los procedimientos en materia de seguridad social $^{54}$. Veinticinco años después, se lamentan también las reglas de competencia de atribución, recogidas en 1978, por el Código de la organización judicial ${ }^{55}$.

La ausencia de definiciones suplementarias también se deplora: así, a propósito de las pretensiones nuevas en apelación, la noción de pretensión que tiende "a los mismos fines que aquellos sometidos al primer juez» ${ }^{56}$. Y se podría mencionar al respecto tantas otras nociones que, al no estar definidas en el Código -el cual sin embargo las utilizasuscitan numerosas interpretaciones que no simplifican la aplicación uniforme de la ley.

Al respecto, es ejemplar el análisis de Jacques Héron para quien «las partes menos afortunadas del Código son precisamente aquellas donde su peso doctrinal es más débil» ${ }^{57}$. Así como mencionar el ejemplo pertinente de la ejecución provisional de las sentencias no obstante apelación, presentada como una «reglamentación invertebrada, dado que carece de idea rectora ${ }^{58}$, lo que autoriza muchas libertades en jurisprudencia, pero también la abundancia de los regímenes especiales como en materia de procedimientos colectivos de insolvencia de las empresas ${ }^{59}$ y de vías de ejecución ${ }^{60}$.

De manera más general, el temor se expresa en el hecho de que el libro III del nuevo Código, el de las Disposiciones particulares a ciertas materias, que deja fuera del Código, numerosos e importantes asuntos como los procedimientos colectivos, el endeudamiento excesivo de los hogares, los alquileres comerciales, la competencia, al ser incompleto no sea el fermento, sino de una decodificación del procedimiento civil, por lo menos de una descomposición del espíritu del Código: en efecto, el riesgo es que reglas especiales, que tienen pretensión de autonomía, se

54 Contenidas en el Código de seguridad social: Véase L. Cadiet, Droit judiciaire privé (Derecho judicial privado), citado anteriormente, No 1869.

55 L. Cadiet, op. cit., No 57.

56 Art. $565^{\circ}$.

57 J. Héron, "Le nouveau Code de procédure civile» (El nuevo Código de procedimientos civil), citado anteriormente, No 14.

58 Ibídem.

59 Ley No 85-98, 25 de enero 1985, Art. No $171^{\circ}$ y Decreto No 85-1388, 27 de diciembre de 1985, Art. No $155^{\circ}$.

60 Decreto No $92-755,31$ de julio 1992 , arts. $30^{\circ}$ y $31^{\circ}$. 
desarrolle olvidando las reglas del derecho común ${ }^{61}$ y que se cree a partir de ese momento, para parafrasear el título de una obra célebre, las condiciones de una revuelta futura del derecho contra el Código.

En otras palabras, son las disposiciones doctrinales del Código las que han resistido mejor el deterioro del tiempo y es como obra de doctrina que el nuevo Código procesal civil se forjará un lugar importante entre las grandes codificaciones. Pero ¿cuál es pues esta doctrina captada por el Código?

\section{La doctrina captada por el nuevo Código procesal civil}

Bello plan, bello código, según la ecuación del decano Philippe Malaurie $^{62}$, como se podría decir bella madera, bello árbol. A la luz de las metáforas, la botánica seguramente está a la cabeza, si así se puede decir. El nuevo código procesal civil, dotado de una madera tan bella, es un bello árbol cuyas fuertes raíces se hunden en un fértil mantillo doctrinal (A) y cuyas ramas fuertes se despliegan dirigiéndose hacia los cielos doctrinales (B).

\section{A. Las bases doctrinales del nuevo Código procesal civil}

El Código procesal civil, no sólo es doctrinal por su forma, su plan y su estilo ${ }^{63}$. «Bien o mal inspirado» también lo es, e incluso lo es en su esencia, en relación a las «ideas que lo animan " ${ }^{64}$ y que el código consagra. Lo que el decano Gérard Cornu llama "el espíritu del código" ${ }^{65}$, en toda la cadena de sus disposiciones, el nuevo Código está matizado con soluciones que son el fruto de puras posiciones doctrinales $\left(1^{\circ}\right)$. Pero estas doctrinas particulares a la obra en el proceso civil no siempre son recibidas como tales, ampliamente protegidas por los «Principios rectores del proceso" sobre el cual se abre el nuevo Código: es allí, en

61 J. Héron, op. cit., No 7-11.

62 Véase supra I, A, $1^{\circ}$.

63 Véase supra I.

64 G. Cornu, op. cit., p. 250.

65 G. Cornu, op. cit., pp. 250-255. 
efecto, en el cofre de esos veinticuatro primeros artículos, donde se expresa la doctrina de conjunto del proceso civil $\left(2^{\circ}\right)$.

\section{Las doctrinas particulares a la obra en el proceso civil}

Como Jacques Héron lo sugirió acertadamente, la "fuerza doctrinal" del nuevo Código no se reduce sólo a los únicos principios rectores del proceso. Ésta también tiene que ver con «la multiplicidad de las posiciones doctrinales diseminadas a lo largo de todo el código, que le dan su sentido y que por el valor permanente que le confieren lo protegen de los ataques del tiempo" ${ }^{66}$.

Por ejemplo, es la idea exótica, de la que se deriva la marca de una doctrina que viene del derecho civil, que «el acto de procedimiento no es otra cosa más que una especie de acto jurídico, en la más pura de las definiciones» ${ }^{67}$, arruinando este "acercamiento radical» «la asimilación deductiva y difundida por demasiado tiempo del procedimiento a la forma ${ }^{68}$. Es el mismo caso de la jurisdicción graciosa, ya que el nuevo Código procesal civil le da el substratum procesal necesario a las hipótesis de jurisdicción graciosa que las reformas contemporáneas del derecho civil de las personas y de la familia había hecho florecer en las disposiciones renovadas del código civil. Aquí como allá, el derecho procesal nuevo, según la expresión del decano Cornu, se ha nutrido esencialmente del derecho sustancial renovado a partir de $1964^{69}$. Se ha civilizado.

Pero esta también es la idea "primitiva" de que la acción es distinta del derecho ${ }^{70}$ o que la apelación no sólo es una vía de reforma que permite volver a juzgar por segunda vez el asunto, entre las mismas

$66 \mathrm{~J}$. Héron, "Le nouveau Code de procédure civile» (El nuevo Código procesal civil), citado anteriormente, p. 87.

67 "Acto de voluntad destinado a producir efectos de derecho, que se desarrollan aquí en un doble plan, aplicándose, por un lado al desarrollo de la instancia, y por el otro, a la materia del litigion: G. Cornu, op. cit., p. 243.

68 G. Cornu, op. cit., y loc. cit.

69 G. Cornu, op. cit., pp. 242-243.

70 Véase H. Motulsky, "Le droit subjectif et l'action en justice» (El derecho subjetivo y la acción en justicia", Archives de philosophie du droit (Archivos de filosofía del derecho), 1964, pp. 215 y ss. 
partes, por las únicas demandas sometidas a los primeros jueces, sino que también es una vía para alcanzar la solución del litigio, tomando en cuenta cierta evolución del mismo y por tanto, algunas pretensiones nuevas $^{71}$.

Se podría proporcionar otras ilustraciones de estas doctrinas particulares, de estas "tendencias»" ${ }^{72}$, que, para algunos, no hacen más que expresar, sobre un asunto dado, la concepción de conjunto del proceso civil consagrado por el nuevo Código.

\section{La doctrina de conjunto del proceso civil}

Esta concepción de conjunto del nuevo Código, está presentada, de entrada, por el primer capítulo, el de los Principios rectores del proceso, "frontón que marca la entrada" y que expresa "la quintaesencia del proceso civil ${ }^{73}$. Estos Principios ya han hecho que muchos escriban al respecto. El Código todavía estaba en gestación cuando Motulsky ya los analizaba ${ }^{74} \mathrm{y}$, veinticinco años más tarde, el Decano Cornu, «como memorial, para una lectura renovada" según su expresión, les daba la palabra ya que «los principios rectores hablan por sí mismos» ${ }^{75}$. «Su nombre es de origen doctrinal» se ha escrito, «no su sustancia» ${ }^{76}$. Entonces, ¿qué dicen?(a) y ¿de dónde vienen?(b).

a) Lo que dicen los Principios rectores de la instancia no tiene nada que ver, como algunos creyeron a partir del decreto del 9 de setiem-

71 Véase J. Vincent, "Les dimensions nouvelles de l'appel en matiére civile» (Las dimensiones nuevas de la apelación en materia civil), recopilación Dalloz 1973, pp. 179 y ss.

72 Véase G. Cornu y J. Foyer, Procedure civile (Procedimiento civil), Presses universitaires de France, 3ra. edición 1996, p. 2.

73 G. Cornu, op. cit., p. 250.

$74 \mathrm{H}$. Motulsky, "La réforme du Code de procédure civile par le décret du 13 octobre 1965 et les principes directeurs du procés" (La reforma del Código procesal civil por el decreto del 13 de octubre de 1965 y los principios rectores del proceso), Semaine Juridique (Semana jurídica), 1966, I, 1996.

75 G. Cornu, "Les principes directeurs du procés civil par eux-memes [...]", en Etudes offertes á Pierre Bellet (Estudios ofrecidos a Pierre Bellet), Litec, 1991, pp. 83-100.

76 G. Cornu, "Les principes directeurs du procés civil par eux-memes [...]", citado anteriormente, p. 83. 
bre de 1971, con un simple ejercicio de estilo que consiste en «haber reunido y condensado [...] para la formación de los futuros estudiantes de derecho, la satisfacción de los juristas y la felicidad de los puristas, los inmortales principios del procedimiento que resultan ser, más o menos, textos dispersos, de la jurisprudencia y de la sabiduría de las naciones $)^{77}$. Esta ilusión había sido inmediatamente denunciada por Motulsky quien había creído correcto precisar que el objetivo que se buscaba era el de "trazar, en presencia de una doctrina dividida y sobre todo- de una jurisprudencia dubitativa, y hasta contradictoria, lo esencial de los límites de la labor del juez y de la distribución de las funciones procesales entre éste y las partes ${ }^{78}$.

Además, esta "carta de distribución de los roles entre el juez y las partes» no es la consagración de un modelo procesal «dirigista " ${ }^{79}$, "predominantemente inquisitivo" ${ }^{80}$, "administrativo y autoritario" ${ }^{81}$ de cómo se había llevado el juicio o el temor expresado inmediatamente después de la promulgación del Código ${ }^{82}$. El código es esencialmente una obra de composición, ni acusatoria ni inquisitorial, dado que esas calificaciones no convienen para nada a lo que básicamente es el proceso civil ${ }^{83}$. Composición puesto que de lo que se trató fue de conciliar los principios liberales de la tradición francesa. Haciendo del proceso el asunto de las partes, y la afirmación de los poderes del juez, a quien le

$77 \mathrm{Ph}$. Bertin, «El decreto del 9 de setiembre de 1971 que involucra reforma parcial del procedimiento civil», Gazette du Palais, 16 de noviembre de 1971, No 3.

$78 \mathrm{H}$. Motulsky, "Prolegómenos para un futuro Código procesal civil: la consagración de los principios rectores del proceso civil por el decreto del 9 de setiembre de 1971 ", recopilación Dalloz, 1972, Crónica, XVII, Nº 6.

79 P. Catala y F. Terré, op. cit., p. 20.

80 R. Perrot, op. cit., p. 33, para el cual ken este equilibrio sutil entre los poderes del juez y los de las partes, no cabe duda que el equilibrio se ha invertido a favor del primero".

81 Temor expresado por J. Vincent y S. Guinchard, op. cit., $20^{\circ}$ edic., 1981, $\mathrm{N}^{\circ}$ $11^{\circ}$ y $24^{\circ}$ edic., $1996, \mathrm{~N}^{\circ} 41$.

82 De la propia declaración de uno de los redactores del nuevo Código, la única "verdadera punta civil inquisitorial» que residiría en el artículo $222^{\circ}$, al 2 , y que autoriza al juez a determinar los hechos pertinentes que se deben probar en la investigación: G. Cornu, "Los principios rectores del proceso civil por ellos mismos...", op. cit. p. 87.

83 H. Motulsky, op. cit., $\mathrm{N}^{\circ} 2$. 
corresponde, como carga más que poder, realizar esta misión de interés general que consiste en llevar a la solución más justa posible del litigio que se debe resolver. La justicia es un servicio público ${ }^{84}$ y la imparcialidad no es pasividad ${ }^{85}$. Sin duda, se le han dado importantes prerrogativas al juez, en la conducción de la instancia, para asegurar su adecuado desarrollo, así como en la propia materia del proceso; es decir, poder impartir plazos y ordenar las medidas necesarias, comprendidas entre éstas, a veces, bajo sanción (Art. $3^{\circ}$ ), capacidad para tomar en consideración en el debate incluso los hechos que las partes no habrían invocado de manera especial para apoyar sus pretensiones (Art. $7^{\circ}$, inciso 2 ), poder de ordenar la producción de un documento (Art. $11^{\circ}$ ) y hasta de oficio, toda medida de instrucción legalmente admisible (Art. $10^{\circ}$ ).

Sin embargo, en primer lugar, esta "exaltación de la labor del juez» como se ha podido calificar ${ }^{86}$, partía casi de cero, cuando el Código no sólo consagró prácticas anteriores: «la novedad sólo es haber reforzado estas reglas en su generalidad ${ }^{87}$; en segundo lugar, las partes, que conservan el poder de iniciativa, correlativamente se vieron obligadas a reconocer el poder de modificar la extensión de la labor del juez, ya sea limitándola a las calificaciones y puntos de derecho a los cuales éstas intentan limitar el debate (Art. $12^{\circ}$ inciso 3) o, por el contrario, aumentándola al conferirle la misión de resolver en calidad de amigable componedor (Art. $12^{\circ}$, inciso 4); en tercer lugar, los poderes del juez están delimitados por la necesidad de respetar el objeto del litigio (Art. $4^{\circ}$ y $5^{\circ}$ ) y, sobre todo, por la necesidad, "en todas las circunstancias", de "observar él mismo el principio de la contradicción» ${ }^{88}$. Estas reglas restablecen el equilibrio. Veinticinco años después, la opinión cada vez mayor, sino unánime, es que los artículos $1^{\circ}$ al $13^{\circ}$ del nuevo Código definen, en realidad, un auténtico principio de cooperación del juez y de las partes en la elaboración del juicio hacia el cual está naturalmente orientado el procedimiento civil ${ }^{89}$.

84 Véase H. Motulsky, op. cit., $\mathrm{N}^{\circ} 2$.

85Informe G. Cornu, "Los principios rectores del proceso civil por sí mismo...», op. cit., p. 91.

86 G. Cornu, "La elaboración del Código procesal civil», op. cit., p. 251.

87 Véase G. Cornu, "Los principios rectores del proceso civil por sí mismos...», citado anteriormente, pp. 90-91.

88 Art. $16^{\circ}$, inciso 1 ).

89 Véase L. Cadiet, Droit judiciaire privé (Derecho judicial privado), op. cit., $\mathrm{N}^{\circ}$ 1100 y ss. 
Esta doctrina, al fin y al cabo, no es el fruto de una generación espontánea, decretada para satisfacer no se sabe qué tipo de satisfacción académica. Los principios rectores del proceso y la concepción del proceso civil que éstos traducen vienen de mucho antes.

b. ¿De dónde vienen entonces los Principios rectores del proceso?

La pregunta es doble.

Es la pregunta, inicial, del origen de su propia existencia al inicio del Código procesal civil. La idea de hacer que el Código comience por principios generales no es nueva: ya había sido abordada durante las codificaciones napoleónicas ${ }^{90}$. La propia expresión, "canonizada" por Motulsky en $1966^{91}$, aparece por primera vez, aparentemente, en 1932, bajo la pluma de René More ${ }^{92}$. Pero con el proyecto de elaborar un nuevo Código es que el enunciado de los principios rectores toma cuerpo $^{93}$. La idea está vinculada a la elección de un plan basado, como hemos visto ${ }^{94}$, en el "postulado de que, bajo estas diversas especies, existe un proceso civil tipo, sometido, como tal, a un cuerpo coherente de reglas constantes" ${ }^{95}$.

90 Como sugerencia, del resto, de la Corte de casación: Véase H. Motulsky, $O p$. cit.,. $\mathrm{N}^{\circ} 7$.

91 Según G. Rouhette, "L'influence en France de la allemande du procés civil et du Code de procédure civile allemand" ( $\mathrm{La}$ influencia de la ciencia alemana del proceso civil y del Código procesal civil alemán en Francia) en Das deutsche Zivilprozessrecht und seine Ausstrahlung auf andere Rechtsordnungen, Gieseking-Verlag, Bielefeld, 1991, pp. 159 y ss. $\mathrm{N}^{\circ} 20$, p. 192.

92 Véase G. Rouhette, op. cit. y loc. cit., que se refiere a R. Morel, Traité élémentaire de procédure civile, (Tratado elemental de procedimiento civil) 1932, 2 ed. 1949, $\mathrm{N}^{\circ}$ 424-427, pp. 345-348. Según G. Rouhette, esto sería una «imitación más que verosímil de la doctrina alemana $[\ldots]$ y por una traducción libre de Grundprinzipien (o de Formative principles)».

93 G. Cornu, "Les principies directeurs du procés civil par eux-memes...» (Los principios rectores del proceso civil por sí mismos...), op. cit., p. 86. Es el Decano Cornu quien, "con pluma segura y precisa» (G. Bolard, "Le nouveau Code de procédure civil francaiss (El nuevo Código procesal civil francés), en Mélanges Joseph Skapski, Cracovia, 1994, pp. 9-22, más precisamente p. 11), garantizará la redacción. De allí el interés histórico de su artículo, "Les principes directeurs du procés civil par eux-memes..." (Los principios rectores del proceso civil por sí mismos), anteriormente citado.

94 Véase supra $1, \mathrm{~A}, 1^{\circ}$.

95 G. Cornu, Op. cit. y loc. cit. 
Resulta más delicado responder a la segunda pregunta, respecto al origen de su sustancia. La búsqueda de influencias siempre es un ejercicio difícil puesto que las ideas que son libres, no se dejan "atrapar» tan fácilmente como las truchas o las palomas. Algunas personas que marcan la pauta permiten identificar, aquí, la influencia de la Z.P.O. alemana y de su concepción supuestamente dirigista del proceso civil que, en realidad, sería más austríaca que alemana ${ }^{96}$, de allí, su repercusión en el Tratado de Glasson y Tissier, al que, por otra parte, René Morel $^{97}$ se acercará. La búsqueda de influencias es una empresa aún más temeraria cuando se trata de identificar las ideas que corresponden a los autores y de lograr la consagración de las mismas en la letra de la ley. Ciertamente podemos observar en los cinco primeros artículos del código la manifestación del principio de impulsión y del principio dispositivo "tal como mencionaba ya Vizioz con la doctrina italiana" ${ }^{98}$. Todavía resulta posible afirmar, como lo hace $\mathrm{M}$. Bolard, que "la tesis de Henri Motulsky, titulada Principios de una realización metódica del derecho privado, constituye el origen primigenio del nuevo código procesal civil»" ${ }^{99}$.

Sin embargo, para lo demás, es necesario hacer algunas precisiones.

Precisiones, en primer lugar, desde el punto de vista general. Los redactores del nuevo Código siempre subrayaron que, "para la mayoría, los principios son fruto de la costumbre donde conservan su enunciado en forma de adagio» ${ }^{100}$. El proceso es el asunto de las partes; $d a$ mihi factum, dabo tibi; jura novit curia... Nada se crea, nada se pierde,

96 Véase G. Rouhette, $O p$. cit., $\mathrm{N}^{\circ} 19$ y ss., que subrayan el carácter aleatorio de la influencia del modelo científico alemán y señala que, en particular, el mismo Henry Motulsky, a pesar de su historia personal, utilizaba la doctrina alemana "con muchisima discresión".

97 Véase G. Rouhette, Op. cit., $N^{\circ} 20$, pp. 190-192.

$98 \mathrm{G}$. Cornu, "Lélaboration du code de procédure civile» (La elaboración del código de procedimiento civil), citado anteriormente, p. 250 y G. Rouhette, Op. cit., No 20, p. 193.

99 G. Bolard. Op. cit., p. 11.

$100 \mathrm{G}$. Cornu, "Los principios rectores del proceso civil por sí mismos [...]", citado anteriormente, pp. 86-89, II, A, así como «La elaboración del código procesal civil», citado anteriormente, p. 251: provienen "de la tradición, donde ya se decian a modo de adagios latinos, y que ofrecian a la reflexión doctrinal la rica sustancia de un dato habitual». 
todo se transforma. Sobre este "aporte costumbrista» es que la doctrina ha trabajado principalmente para liberar así "todo el potencial» "inspirándose en las exigencias de una justicia mejor» ${ }^{101}$. Pars translatitia $y$ pars nova, íntimamente ligados ${ }^{102}$. De manera ingeniosa, Motulsky pretendía incluso que «la reforma del proceso civil se había iniciado antes de la promulgación del Código procesal civil de $1806{ }^{103}$. En efecto, cada uno sabe muy bien, según Portalis, que «los códigos de los pueblos se hacen con el tiempo; pero realmente, uno no los hace» ${ }^{104}$.

En cuanto a los detalles de las disposiciones, también sería necesario distinguir $y$, de manera particular, en relación al asunto todavía hoy en día controvertido de la simple facultad o de la imperiosa obligación, para un juez, de destacar de oficio los medios de derecho: ‘acaso el juez puede o debe plantear de oficio los de esta naturaleza? ${ }^{105}$. En su versión original, el Código había hecho una buena elección, entonces, no entre dos concepciones doctrinarias de la labor del juez, una pasiva y la otra activa, sino entre dos versiones absoluta y relativa, de la misma concepción doctrinal de la labor del juez, aquella de un juez activo y que se aprueba o no, esta elección era la de la simple facultad, lo que Motulsky, en sus Prolegómenos [...], había reconocido lamentándolo. El tiempo hará su parte y los historiadores del derecho procesal la suya. Finalmente, sin buscar la paternidad, contentémonos con observar la posterioridad de los principios rectores a través de la influencia positiva doctrinal del nuevo Código procesal civil.

101 G. Cornu, Op. cit., y loc. cit. - Véase también G. Cornu y J. Foyer, Op. cit., p.19.

102 G. Cornu y J. Foyer, Op. cit., N 5, p. 15.

$103 \mathrm{H}$. Motuksky, "Prolegómenos para un futuro código procesal civil [...]", citado anteriormente, $\mathrm{N}^{\circ} 1$ y nota 2.

104 J.-E.-M. Portalis, Discours préliminaire sur le projet de Code civil (Discurso preliminar sobre el proyecto del Código civil), presentado el ler. año.

105 Comparar. H. Motulsky, «Prolegómenos para un futuro código procesal civil [...]», citado anteriormente, espec. $N^{\circ} 45-46$, que veían en esto una obligación, y $G$. Cornu, "Los principios rectores del proceso civil por sí mismo [...]", citado anteriormente, pp. 89-90: que veían en esto una facultad, "un perfeccionamiento absolutista que no debía hacer del capítulo preliminar el lugar del derecho inflexible». 


\section{B. La proyección doctrinal del nuevo Código procesal civil}

Es indiscutible que el nuevo Código procesal civil ha marcado y sigue marcando época. A esta proyección se puede atribuir el desarrollo considerable, a partir del nuevo Código, de obras generales de procedimiento civil, manuales y $\operatorname{cursos}^{106}$, así como revistas dedicadas especialmente al proceso como por ejemplo, Procedures (Procedimientos) ${ }^{107}$. Pero si el hecho ya está dado, ¿cómo medir la proyección doctrinal del nuevo Código procesal civil? La tarea no es fácil, al menos por dos razones. En primer lugar se puede pensar, como Rouhette, que «el asunto de la influencia de un Código de procedimiento parece en vías de extinción, debido al desarrollo de las fuentes supra legislativas del derecho procesal: Constitución y Convención europea de los derechos del hombre» ${ }^{108}$, al que se puede igualmente añadir el derecho comunitario, convencional y derivado ${ }^{109}$. Además, esta proyección se muestra rara vez como tal en la esfera de la teoría pura del derecho procesal. Se

106 La observación la hizo G. Bolard, Op. cit.,. p. 11, nota 7: aparte del Tratado de derecho judicial privado de Henry Solus y de Roger Perrot, cuya edición, iniciada en 1961 en Sirey, todavía no tenía un tomo relativo al procedimiento (aparecerá después, con el tomo III, en 1991) y el curso de Derecho judicial privado, impartido en la Universidad de París II, por Roger Perrot y publicado por Los cursos de derecho, no había prácticamente nada, según el orden establecido de las evoluciones recientes, que el compendio de Procedimiento civil publicado en Dalloz por Jean Vincent, reunido en 1981 Serge Guinchard, y el manual de Procedimiento civil y vias de ejecución de Pierre Catala y Francois Terré que, paradógicamente, no tendrá nuevas ediciones después de la segunda aparecida en 1976. Las otras obras vendrán con el nuevo Código: G. Couchez, Procedimiento civil, Sirey, 1981; H. Croze y C. Morel, Procedimiento civil, Presses universitaires de France, 1988; J. Héron, Derecho judicial privado, Montchrestien, 1991; L. Cadiet, Derecho judicial privado, Montchrestien, 1991; L. Cadiet, Derecho judicial privado, Litec, 1992.

107 Revista mensual de las Editions du Juris-classeur, creada en 1996 y dirigida por R. Perrot y H. Croze.

108 G. Rouhette, $O p$. cit., $\mathrm{N}^{\circ} 25$.

109 Véase H. Muir-Watt, Enciclopedia jurídica Dalloz, Rep. Proc. Civ., V «Droit international et procédure civile» (Derecho internacional y procedimiento civile. J. Normand, "Le rapprochement des procédures civiles dans l'Union européenne» (El acercamiento de los procedimientos civiles en la Unión europea) en Cour de cassation (Corte de casación), El nuevo Código de procedimiento civil: veinte años después, La documentación francesa, 1998, pp. 265-283. 
manifiesta, por lo general, de manera difusa, en el terreno del derecho positivo en sí. Cuando un Código es tan doctrinal como el nuevo Código procesal civil, el modelo legislativo y el modelo científico están necesariamente ligados. Hechas estas salvedades, la proyección doctrinal del nuevo Código procesal civil puede buscarse en dos direcciones, la del procedimiento civil $\left(1^{\circ}\right)$, y la de los otros procedimientos $\left(2^{\circ}\right)$.

$\left.1^{\circ}\right)$ En el procedimiento civil

La apreciación de la proyección del Código lleva primero a interrogarse, en el terreno mismo del procedimiento civil, sobre el devenir de las soluciones consagradas por éste. Aun cuando éstas no serían siempre innovaciones del Código, por lo menos éste, en el régimen que él les ha reservado, había optado por favorecer el desarrollo. Entonces, se debe sopesar: sopesar su éxito, como el procedimiento de recurso de urgencia, la ejecución provisional de los juicios que una reciente relación proponía incluso generalizar al conjunto de juicios de primera instancia ${ }^{110}$, el mandamiento de pagar que la misma relación proponía hacer extensivo al tribunal de primera instancia ${ }^{111}$; sopesar su fracaso como la demanda conjunta y la amigable composición judicial; sopesar su resurrección, deseada a falta de ser siempre probada, como la conciliación cuyo último avatar, la mediación, tienen ya un lugar en el rango de las disposiciones comunes a todas las jurisdicciones ${ }^{112}$; sopesar su pobre aplicación, como el procedimiento con fecha determinada, la investigación, la consulta (con excepción del alza súbita de los precios, propiamente excepcional, del amicus curiae ${ }^{I 3}$ y así podríamos seguir con la relación. Algunas disposiciones del nuevo Código parecen incluso nunca haber sido objeto de una sola aplicación: con el refuerzo sin embargo útil de la informática documental, sucede que las ediciones comerciales del Código sean todavía vírgenes, bajo más de un artículo, de toda referencia de jurisprudencia.

110 J.-M. Coulon, Réflexions et proposition sur la procédure civiles (Reflexiones y propuestas sobre el procedimiento civil), La documentación francesa, 1997, pp. 108-109.

111 J.-M. Coulon, Op. cit., pp. 67-68.

112 Véase nuevo C. proc. Cir., Art. 131-1 a 131-15, que compone un Título VI bis, La mediación, que sigue al Titulo VI, La conciliación.

113 Véase G. Cornu, «la elaboración del código procesal civil» op. cit., pp. 254-255. 
Baste hacer aquí dos observaciones más generales.

La primera observación es que sobre todo a propósito de la labor del juez y del procedimiento del arreglo de los asuntos que la propia concepción del proceso civil está en el centro de los debates actuales y del sueño, a menudo acariciado, de «otro proceso posible», dejado íntegramente en manos de las partes ${ }^{114}$. Esta impugnación recurrente es, a su manera, un índice de la proyección doctrinal del Código y es importante, al respecto, que la relación sobre el procedimiento civil remitido al ministro de Justicia, por Jean-Marie Coulon se haya presentado como una empresa de consolidación de la doctrina del nuevo Código de procedimiento civil cuando "la crisis probada de la justicia civil [...] amenaza las propias bases del nuevo Código procesal civil» ${ }^{115}$.

La segunda observación es que la síntesis realizada por los principios rectores del proceso no estaba concebida para expresar "un derecho procesal que, a un grado superior de generalidad, llega a la teoría del proceso, cualquiera que sea el modo (civil, penal, administrativo o arbitral)» ${ }^{116}$. Cada uno ve en esto, por lo menos, un "derecho común procesal para el derecho privado" ${ }^{117}$ y no sólo por los litigios presentados ante las jurisdicciones estatales. Ya que es de orden público, el núcleo sólido de los principios rectores, primi inter pares, se impone también el arbitraje ${ }^{118}$ y el florecimiento de los modos alternativos de reglamento de los conflictos (y los MARC, versión francesa de los ADR) suscita actualmente la investigación de los "principios rectores" del reglamento amigable de los litigios ${ }^{119}$. Los principios rectores del proce-

114 Véase R. Martin, "Un autre procés possible ou ¿est-il interdit de rever?” (¿Otro proceso posible en el que está prohibido soñar?), Revista trimestral de derecho civil, 1994, pp. 557 y ss.

115 J.-M- Coulon, Op. cit., p. 14.

$116 \mathrm{G}$. Cornu, «Los principios rectores del proceso civil por sí mismos [...]»,op. cit., pp. 84-85.

117 J. Vincent y S. Guinchard, Op. cit., 24 edición 1996, No 36.

118 Véase Art. $1460^{\circ}$, inciso 2, que remite a los principios enunciados en los artículos $4^{\circ}$ al $10^{\circ}, 11^{\circ}$ (inciso 1) y $13^{\circ}$ al $21^{\circ}$ : aquellos que «abordando la esencia de la acción de juzgar, se refieren a todo juez" (G. Cornu, op. cit., p. 84, nota 7).

119 A veces diferentes, para los principios accesorios, como el secreto en el lugar de la publicidad; a veces comunes, para los principios esenciales, como el respeto de la contradicción. 
so no hablan solamente de sí mismos; también se imponen por sí mismos $y$, a través de "fondos de referencia» ${ }^{120}$, el inicio final de la proyección del nuevo Código procesal civil es justamente proporcionado por la observación de su influencia espontánea incluso más allá del mismo proceso civil.

$\left.2^{\circ}\right)$ En los otros procedimientos

La influencia es particularmente clara en el Procedimiento penal que siempre, de reforma en contra reforma, busca un código moderno. Pero la Constitución francesa de 1958, desde este punto de vista, no es para él tan favorable como para el procedimiento civil en la medida en que el procedimiento penal es de competencia del Parlamento mientras que el procedimiento civil emana del poder reglamentario del Gobierno. Es importante destacar, en todo caso, que el concepto de principio rector del proceso ha conquistado el corazón de muchos penalistas y que uno de los grandes proyectos de reforma de la institución penal ha hecho de los principios rectores del proceso penal el núcleo sólido de las propuestas de reforma ${ }^{121}$. Con el concurso del derecho al proceso equitativo, los principios rectores se internacionalizan allí incluso al conjunto de los procedimientos penales de Europa ${ }^{122}$. En tal caso, sin embargo que la empresa es menos fácil que en el procedimiento civil, existe la misma preocupación de composición, la misma búsqueda de equilibrio entre una concepción acusatoria y una concepción inquisitiva y, como en el nuevo Código procesal civil, el refuerzo de lo contradictorio es el instrumento principal de la reforma prevista. Estos diferentes proyectos por lo demás acaban de terminar, en gran parte, porque una ley muy reciente del 15 de junio del año 2000 acaba de introducir

120 G. Cornu, op. cit., p. 85.

121 Véase M. Delmas-Marty (dir), La mise en état des affaires pénales (El arreglo de los asuntos penales), La documentación francesa, 1991: la Comisión de justicia penal y derechos del hombre ya había sacado, de la Constitución francesa y de la Convención europea de los derechos del hombre, diez principios fundamentales para inscribirlos en el encabezado del código de procedimiento penal.

122 Véase M. Delmas-Marty (dir), Procedimientos penales de Europa, Presses universitaires de France, 1995. 
al inicio del Código procesal penal un nuevo artículo preliminar que expone los principios rectores del proceso penal ${ }^{123}$.

¿Cómo podía el procedimiento administrativo, en estas condiciones, escapar a esta influencia? Esto no se podía prever. Los principios del derecho al proceso equitativo consagrados por las convenciones internacionales se aplican también a lo contencioso administrativo. La codificación reciente del procedimiento administrativo por una ordenanza del 4 de mayo del año 2000 fue pues el motivo para inaugurar el novísimo Código de la justicia administrativo de un título preliminar que se compone de once artículos que contienen los principios rectores del proceso administrativo ${ }^{124}$.

Aunque la sustancia de estos nuevos principios rectores no es necesariamente la misma más que en materia civil, es una suerte de regalo de cumpleaños que el procedimiento penal y el procedimiento administrativo ofrecen de esta manera al procedimiento civil veinticinco años después.

123 L. N $N^{\circ} 2000-516$ del 15 de junio del año 2000 que refuerza la protección de la presunción de inocencia y los derechos de las víctimas, Diario oficial 16 de junio del año 2000, pp. 9038 y ss.

124 Ord. No 2000-387 del 4 de mayo del año 2000, Diario oficial, 7 de mayo del 2000 , pp. 6903 y ss. incluidos los anexos. 